\title{
Recreating the inferior vena cava with a patient-specific biodegradable conduit
}

\author{
Gregory J. Bittle, MD, and Sunjay Kaushal, MD, PhD
}

\footnotetext{
From the Division of Cardiac Surgery, Department of Surgery, University of Maryland School of Medicine, Baltimore, Md.

Disclosures: Authors have nothing to disclose with regard to commercial support.

Received for publication Nov 14, 2016; accepted for publication Nov 17, 2016; available ahead of print Jan 18 2017.

Address for reprints: Sunjay Kaushal, MD, PhD, Division of Cardiac Surgery, Department of Surgery, University of Maryland School of Medicine, 110 S Paca St, Baltimore, MD 21201 (E-mail: skaushal@som.umaryland. edu).

J Thorac Cardiovasc Surg 2017; 153:933

$0022-5223 / \$ 36.00$

Copyright (c) 2016 by The American Association for Thoracic Surgery

http://dx.doi.org/10.1016/j.jtcvs.2016.11.045
}

The Fontan operation with an extracardiac conduit for the total cavopulmonary connection requires creation of a bridge between the inferior vena cava and the pulmonary artery. Existing prosthetic grafts in this position are far from ideal, carrying the risks of thromboembolism, neointimal hyperplasia and obstruction, and the unsatisfying compromises involved in sizing a static conduit in a growing child. We continue to tolerate these prosthetic grafts for Fontan completion, however, because of their adaptability and ease of use, generally favorable hemodynamics, and lower risk of refractory atrial arrhythmias.

In this issue, Fukunishi and colleagues ${ }^{1}$ describe a custom-fabricated biodegradable tube graft specifically designed for inferior vena cava interposition in Fontan-type operations, which has the potential to alleviate many of the risks associated with traditional grafts. This group's experience with similar devices actually dates back to $2001,{ }^{2}$ when an obstructed hepatopulmonary conduit was replaced with an absorbable tubular scaffold seeded with autologous mononuclear cells. This human clinical work has continued for more than a decade, yielding a series of 25 children followed up for an average of 5.8 years, with encouraging patency rates, responsiveness to balloon dilation, and overall adequate clinical outcomes.

Although it builds on previous experience, the current ovine model of Fukunishi and colleagues ${ }^{1}$ marks a distinctly new stage in the evolution of tissue-engineered vascular grafts. First, this graft is custom spun according to patient-specific imaging data, which will allow careful fitting to complex anatomy and may even provide a platform by which computational fluid dynamics analysis may be used to optimize cavopulmonary flow patterns for a particular patient. Second, the graft is no longer seeded in advance with cellular material. Despite this seemingly fundamental change in preparation, Fukunishi and colleagues $^{1}$ provide histologic evidence both of wellorganized cellular replacement of the scaffold material and of acceptable strength and flow characteristics at

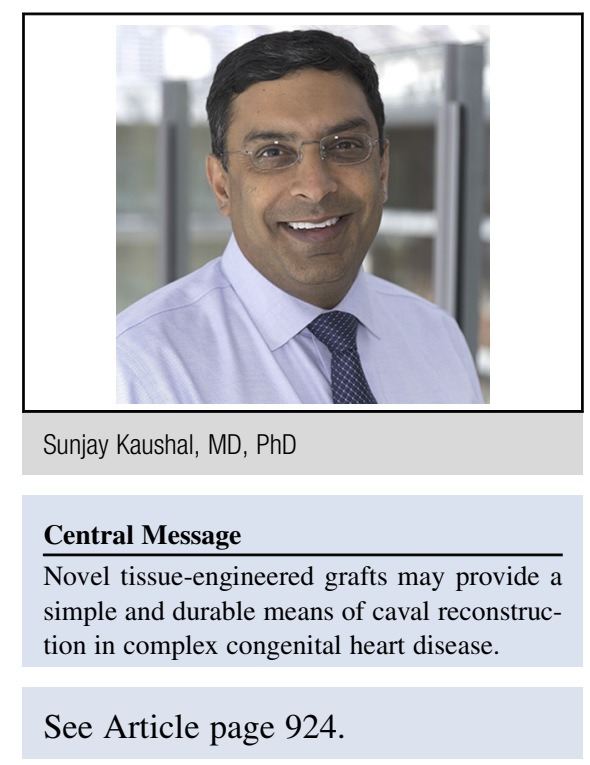

6-month follow-up, with no long-term requirement for anticoagulation. Safely eliminating the laboratory expertise, patient discomfort, storage limitations, and cost associated with stem cell isolation and seeding would allow what was once a niche product fabricated ad hoc at a research institution to become readily available at any hospital.

In the pursuit of a patient-specific therapy for a complex condition, Fukunishi and colleagues ${ }^{1}$ have demonstrated a product that is more versatile and more biocompatible than anything currently available to our patients. Concerns regarding late stenosis, thrombus formation, and growth remain unanswered, and the potential for this material to function in other anatomic positions or in human patients has not been addressed. Even so, this sophisticated iteration of the tissue-engineered vascular graft may bring us closer to a device that better recapitulates the unassuming reliability of the normal, native vena cava.

\section{References}

1. Fukunishi T, Best CA, Sugiura T, Opfermann J, Ong CS, Shinoka T, et al. Preclinical study of patient-specific cell-free nanofiber tissue-engineered vascular grafts using 3-dimensional printing in a sheep model. J Thorac Cardiovasc Surg. 2017; 153:924-32.

2. Naito Y, Imai Y, Shin'oka T, Kashiwagi J, Aoki M, Watanabe M, et al. Successful clinical application of a tissue-engineered graft for extracardiac Fontan. J Thorac Cardiovasc Surg. 2003;125:419-20.

3. Hibino N, McGillicuddy E, Matumura G, Ichihara Y, Naito Y, Breuer C, et al. Late-term results of tissue-engineered vascular grafts in humans. J Thorac Cardiovasc Surg. 2010;139:431-6. 